OPEN ACCESS

Edited by:

Nicholas Cauwenberghs,

KU Leuven, Belgium

Reviewed by:

Zaixin Yu,

Central South University, China

Guo-wei Tu,

Fudan University, China

*Correspondence:

Rui Zhang

zhangrui@tongji.edu.cn

Lan Wang

wanglan198212@163.com

tThese authors have contributed equally to this work

Specialty section:

This article was submitted to

General Cardiovascular Medicine,

a section of the journal

Frontiers in Cardiovascular Medicine

Received: 22 July 2021 Accepted: 25 October 2021 Published: 22 November 2021

Citation:

Gong S-G, Wu W-H, Li C, Zhao Q-H, Jiang R, Luo C-J, Qiu H-L, Liu J-M, Wang $L$ and Zhang $R$ (2021) Validity of the ESC Risk Assessment in Idiopathic

Pulmonary Arterial Hypertension in

China.

Front. Cardiovasc. Med. 8:745578.

doi: 10.3389/fcvm.2021.745578

\section{Validity of the ESC Risk Assessment in Idiopathic Pulmonary Arterial Hypertension in China}

\author{
Su-Gang Gong ${ }^{1+}$, Wen-Hui Wu ${ }^{1+}$, Chao Li $^{2}$, Qin-Hua Zhao ${ }^{1}$, Rong Jiang ${ }^{1}$, Ci-Jun Luo ${ }^{1}$, \\ Hong-Ling Qiu ${ }^{1}$, Jin-Ming Liu ${ }^{1}$, Lan Wang ${ }^{1 *}$ and Rui Zhang ${ }^{1 *}$ \\ ${ }^{1}$ Department of Pulmonary Circulation, Shanghai Pulmonary Hospital, Tongji University School of Medicine, Shanghai, China, \\ ${ }^{2}$ Tongji University School of Medicine, Shanghai, China
}

Background: The 2015 European pulmonary hypertension $(\mathrm{PH})$ guidelines recommend a risk stratification strategy for pulmonary arterial hypertension (PAH). We aimed to investigate the validation and potential prognostic information in Chinese patients.

Methods: The risk assessment variables proposed by the $\mathrm{PH}$ guidelines were performed by using the $\mathrm{WHO}$ function class, 6-min walking distance, brain natriuretic peptide or its $\mathrm{N}$-terminal fragment, right arterial pressure, cardiac index, mixed venous saturation, right atrium area, pericardial effusion, peak oxygen consumption, and ventilatory equivalents for carbon dioxide. An abbreviated version also was applied.

Results: A total of 392 patients with idiopathic PAH (IPAH) were enrolled between 2009 and 2018. After a median interval of 13 months, re-evaluation assessments were available for 386 subjects. The PAH guidelines risk tool may effectively discriminate three risk groups and mortality $(p<0.001)$ both at the baseline and re-evaluation. Meanwhile, its simplified risk version was valid for baseline and accurately predicted the risk of death in all the risk groups $(p<0.001)$. At the time of re-evaluation, the percentage of low-risk group has an increase, but a greater proportion achieved the high-risk group and a lesser proportion maintained in the intermediate-risk group.

Conclusion: The 2015 European PH guidelines and its simplified version risk stratification assessment present an effective discrimination of different risk groups and accurate mortality estimates in Chinese patients with IPAH. Changes of risk proportion at re-evaluation implicated that natural treatment decisions may not be consistently with goal-oriented treatment strategy.

Keywords: pulmonary arterial hypertension, idiopathic pulmonary arterial hypertension, risk assessment, guideline, prognosis

\section{INTRODUCTION}

The assessment of the prognosis of patients has been considered as an important section in patients with pulmonary arterial hypertension $(\mathrm{PAH})$; different baseline and follow-up variables have been utilized individually or combined to predict outcome. Up to date, the 2015 European Society of Cardiology (ESC)/European Respiratory Society (ERS) pulmonary hypertension (PH) guidelines proceedings summarized risk stratification strategy advances (1), each focusing on 
different countries or registries, including the Registry to Evaluate Early and Long-Term Pulmonary Arterial Hypertension Disease Management (REVEAL) studies $(2,3)$, the Swedish PAH Registry (4), the Comparative, Prospective Registry of Newly Initiated Therapies for Pulmonary Hypertension (COMPERA) Registry (5), and the French PH Network (FPHN) (6). The updated analysis of risk stratification recommended a flexible and comprehensive approach by using the clinical features such as right ventricular function, hemodynamic parameters, biomarkers, and exercise. Based on the cutoff values gathered from the 2015 ESC/ERS guidelines, three risk categories were defined as a low-, intermediate-, or high-risk group (1).

The accuracy of this risk assessment strategy has been validated by the COMPERA Registry and mortality rate was significantly different between the three risk strata in baseline and follow-up (5). However, the COMPERA study used an abbreviated version risk analysis including six variables such as the WHO function class (FC), 6-min walk distance (6MWD), brain natriuretic peptide (BNP) or N-terminal proBNP (NTproBNP), right arterial pressure (RAP), cardiac index (CI), and mixed venous oxygen saturation $\left(\mathrm{S}_{\mathrm{V}} \mathrm{O}_{2}\right)$, not capturing disease progression, syncope, echocardiography, and cardiopulmonary exercise testing (CPET) data. These findings confirm and extend previous study by Kylhammar et al. (4), who used the same subset of parameters [plus right atrial area and the presence/absence of pericardial effusion (PE)]. Although simplified variables could discriminate the risk groups, the most reliable dataset from echocardiography and CPET needed to determine (1).

TABLE 1 | Variables and cutoff values from the risk assessment from the ESC/ERS 2015 guidelines ${ }^{*}$.

\begin{tabular}{|c|c|c|c|}
\hline & Low risk & $\begin{array}{l}\text { Intermediate } \\
\text { risk }\end{array}$ & High risk \\
\hline WHO FC & I, II & III & IV \\
\hline 6MWD, meter & $>440$ & $165-440$ & $<165$ \\
\hline BNP, ng/L & $<50$ & $50-300$ & $>300$ \\
\hline NT-proBNP, ng/L & $<300$ & $300-1,400$ & $>1,400$ \\
\hline \multicolumn{4}{|l|}{ Hemodynamics } \\
\hline RAP, $\mathrm{mmHg}$ & $<8$ & $8-14$ & $>14$ \\
\hline $\mathrm{Cl}, \mathrm{L} / \mathrm{min} / \mathrm{m}^{2}$ & $\geq 2.5$ & $2.0-2.4$ & $\leq 2.0$ \\
\hline $\mathrm{S}_{\mathrm{V}} \mathrm{O}_{2}, \%$ & $>65$ & $60-65$ & $<60$ \\
\hline \multicolumn{4}{|c|}{ Imaging (echocardiography) } \\
\hline $\mathrm{RA}$ area, $\mathrm{cm}^{2}$ & $<18$ & $18-26$ & $>26$ \\
\hline Pericardial effusion & No & No or minimal & Yes \\
\hline \multicolumn{4}{|c|}{ Cardio-pulmonary exercise testing } \\
\hline Peak $\mathrm{VO}_{2}, \mathrm{~mL} / \mathrm{min} / \mathrm{kg}$ & $\begin{array}{c}>15(>65 \% \\
\text { pred.) }\end{array}$ & $\begin{array}{c}11-15 \\
\text { (35-65\% } \\
\text { pred.) }\end{array}$ & $\begin{array}{c}<11(<35 \% \\
\text { pred.) }\end{array}$ \\
\hline VENCO 2 slope & $<36$ & $36-44.9$ & $\geq 45$ \\
\hline
\end{tabular}

*Simplified version included the WHO FC, 6MWD, NT-proBNP, BNP, RAP, Cl, and $\mathrm{S}_{V} \mathrm{O}_{2} \%$. $B N P$, brain natriuretic peptide; Cl, cardiac index; ESC, European Society of Cardiology; ERS, European Respiratory Society; 6MWD, 6-minute walk distance; NT-proBNP, Nterminal pro-BNP; $R A$, right atrium; $R A P$, right atrial pressure; $\mathrm{SvO}_{2}$, mixed venous oxygen saturation; $V E N \mathrm{CO}_{2}$, ventilatory equivalent for carbon dioxide; $\mathrm{VO}_{2}$, oxygen consumption; FC, function class.
Patients with PAH usually show a typical pattern with low peak oxygen uptake [peak oxygen consumption $\left(\mathrm{VO}_{2}\right)$ ], providing prognostic information and therapeutic decision-making $(1,7)$. Echocardiography remained an important determinant as right ventricular function was key prognostic variables $(8,9)$. Similarly, the risk assessment of the French PH Network proposed by the European PH guidelines in patients with idiopathic PAH (IPAH) was available to work at baseline and follow-up (6). In fact, the risk stratification tool itself has a level of evidence C; also, the cutoff points are derived from several studies (1). However, it is unknown to validate the efficiency of this instrument in a real-world cohort in specific treatment era, especially in China.

The principle aim of this study was to apply the risk assessment from the 2015 ESC/ERS guidelines to a newly diagnosis cohort of patients with IPAH in China. We attempted to test the discrimination of the risk instrument presented in guidelines and to explore the potential prognostic changes at follow-up.

\section{MATERIALS AND METHODS}

\section{Study Patients}

All the newly diagnosed patients with IPAH $(\geq 18$ years of age at diagnosis) were retrospectively reviewed in the Shanghai Pulmonary Hospital between January 2009 and September 2018. IPAH at baseline was set by right heart catheterization (RHC) according to standard criteria: a mean pulmonary artery pressure (mPAP) $\geq 25 \mathrm{~mm} \mathrm{Hg}$ and pulmonary vascular resistance $(\mathrm{PVR})>3$ Wood units at rest in the presence of a normal pulmonary artery wedge pressure (PAWP) $\leq 15 \mathrm{~mm} \mathrm{Hg}$ (1). Patients were excluded if they have definite causes for PAH such as connective tissue disease and congenital heart disease, those with portopulmonary hypertension, chronic pulmonary thromboembolism, and pulmonary hypertension due to left heart diseases and lung diseases and/or hypoxemia. Major endpoint was defined as all-cause mortality and no patients received lung or heart-lung transplantation. This study was conducted according to the principles of the Declaration of Helsinki and was approved by the Shanghai Pulmonary Hospital Ethics Committee (K19-054). Written informed consent was obtained from all the participants.

\section{Risk Stratification}

Risk assessment was performed according to the 2015 ESC/ERS $\mathrm{PH}$ guidelines and patients were categorized as "low risk," "intermediate risk," or "high risk" in Table 1 (5). An abbreviated version of this guideline risk stratification strategy used the WHO FC, 6MWD, BNP or NT-proBNP, RAP, CI, and $\mathrm{S}_{\mathrm{V}} \mathrm{O}_{2}$. The cutoff values proposed in the guidelines were graded as 1,2 , and $3(1=$ low risk, $2=$ intermediate risk, and 3 $=$ high risk). When the baseline 6-MWD did not detect, it was considered as a grade 3 (4). For each patient, the sum of all the grades was divided by the number of available variables. The mean grade was rounded to the next integer to define the risk group. For the follow-up risk stratification, 
TABLE 2 | Characteristics of patients with IPAH in baseline risk stratification.

\begin{tabular}{|c|c|c|c|c|c|}
\hline & $N$ & Low risk & Intermediate risk & High risk & All \\
\hline Subjects, $n$ (\%) & & $96(25)$ & 267 (68) & $29(7)$ & 392 \\
\hline Age, years & & $35 \pm 14$ & $42 \pm 16$ & $39 \pm 16$ & $40 \pm 16$ \\
\hline Female, $n(\%)$ & & $70(73)$ & $180(67)$ & $14(48)$ & 264(67) \\
\hline $\mathrm{BMl}, \mathrm{kg} / \mathrm{m}^{2}$ & & $23 \pm 6$ & $22 \pm 4$ & $23 \pm 3$ & $23 \pm 4$ \\
\hline \multicolumn{6}{|l|}{ WHO FC, $n(\%)$} \\
\hline Class I-II & & $69(72)$ & $63(24)$ & $0(0)$ & $132(34)$ \\
\hline Class III & & $27(28)$ & $188(70)$ & $19(66)$ & $234(60)$ \\
\hline Class IV & & $0(0)$ & $16(6)$ & $10(35)$ & $26(7)$ \\
\hline 6MWD, meters & 392 & $436 \pm 97$ & $364 \pm 100$ & $280 \pm 95$ & $379 \pm 107$ \\
\hline BNP, ng/L & 164 & $46(24,94)$ & $262(149,438)$ & $661(306,880)$ & $211(65,426)$ \\
\hline NT-proBNP, ng/L & 250 & $162(40,267)$ & $1096(542,1892)$ & $2428(1949,3771)$ & $748(255,1679)$ \\
\hline \multicolumn{6}{|l|}{ Hemodynamics } \\
\hline $\mathrm{RAP}, \mathrm{mmHg}$ & 389 & $4(2,7)$ & $6(4,10)$ & $15(12,17)$ & $6(3,10)$ \\
\hline mPAP, mmHg & 392 & $53(45,63)$ & $58(50,69)$ & $63(56,80)$ & $58(48,68)$ \\
\hline PAWP, mmHg & 392 & $7(6,10)$ & $8(5,10)$ & $10(7,11)$ & $8(5,10)$ \\
\hline $\mathrm{Cl}, \mathrm{L} / \mathrm{min} / \mathrm{m}^{2}$ & 388 & $3.2(2.8,3.7)$ & $2.2(1.9,2.7)$ & $1.6(1.5,1.8)$ & $2.4(1.9,3.0)$ \\
\hline PVR, Wood units & 392 & $9(7,12)$ & $15(11,18)$ & $20(16,26)$ & $14(9,18)$ \\
\hline $\mathrm{S}_{\mathrm{V}} \mathrm{O}_{2}, \%$ & 388 & $72(68,76)$ & $60(56,65)$ & $46(42,52)$ & $62(56,69)$ \\
\hline \multicolumn{6}{|c|}{ Echocardiographic variables } \\
\hline $\mathrm{RA}$ area, $\mathrm{cm}^{2}$ & 235 & $16(13,20)$ & $23(18,33)$ & $38(29,47)$ & $22(16,30)$ \\
\hline No PE, $n(\%)$ & & $90(94)$ & $163(61)$ & $7(24)$ & $260(66)$ \\
\hline Minimal PE, $n(\%)$ & & $1(1)$ & $73(27)$ & $15(52)$ & $89(25)$ \\
\hline PE, $n(\%)$ & & $0(0)$ & $5(2)$ & $3(10)$ & $8(2)$ \\
\hline \multicolumn{6}{|c|}{ Cardiopulmonary exercise testing } \\
\hline Peak $\mathrm{VO}_{2}, \mathrm{~mL} / \mathrm{min} / \mathrm{kg}$ & 100 & $18 \pm 4$ & $12 \pm 3$ & $9 \pm 2$ & $14 \pm 4$ \\
\hline VENCO 2 slope & 100 & $36 \pm 7$ & $62 \pm 36$ & $79 \pm 22$ & $56 \pm 33$ \\
\hline \multicolumn{6}{|c|}{ Initial therapies (within 3 months after diagnosis), $n$ (\%) } \\
\hline No specific/CCB therapy & & $13(14)$ & $20(8)$ & $0(0)$ & $33(8)$ \\
\hline Monotherapy & & $68(71)$ & $169(63)$ & $21(72)$ & $258(66)$ \\
\hline Combination therapy & & $15(16)$ & $78(29)$ & $8(28)$ & $101(26)$ \\
\hline
\end{tabular}

Values are expressed as mean $\pm S D$, medians (interquartile range), or $n(\%)$, unless otherwise stated.

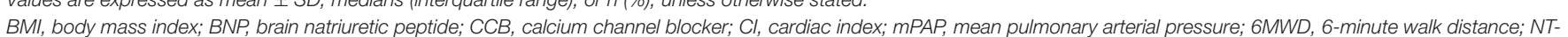

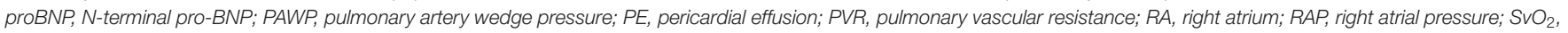
mixed venous oxygen saturation; VENCO $\mathrm{V}_{2}$, ventilatory equivalents for carbon dioxide; $\mathrm{VO}_{2}$, oxygen consumption; FC, function class; IPAH, idiopathic pulmonary arterial hypertension.

we chose the visit that included follow-up hemodynamics after the baseline risk assessment at least 3 months. If no hemodynamic follow-up was available, we selected the follow-up visit that contained most of the data such as echocardiography or CPET. Variables listed in the guidelines that are not captured both at the baseline and follow-up are disease progression and syncope.

\section{Statistical Analysis}

Continuous variables are expressed as mean \pm SD or medians with corresponding 25 th and 75 th percentiles [interquartile range (IQR)]. Categorical variables are expressed as numbers and percentages. When data were not normally distributed, a nonparametric test was used. Changes between baseline and reevaluation were assessed by using the chi-squared test where appropriate. Survival analyses were performed by using the Kaplan-Meier method, truncated at 5 years, and were compared by using the log-rank test. Survival time was calculated from the date of diagnostic RHC to the date of final follow-up and reevaluation to final follow-up. Survival was compared for patients who were remained in the low-, intermediate-, or high-risk group, respectively, improved to the low- or intermediate-risk group, or worsened to the intermediate- or high-risk group. The univariate and multivariate Cox proportional hazards regression analysis was performed to assess the risk of death by using the respective low-risk group as reference. Patients were censored at termination December 31, 2018. A $p$-value $<0.05$ was considered as statistically significant. All the analyses were performed by using the Statistical Package for the Social Sciences (SPSS) version 14.0 statistical software package (SPSS, Chicago, Illinois, USA).

\section{RESULTS}

\section{Study Patients}

The baseline data reviewed total newly 392 patients with IPAH who fulfilled the criteria including 11 variables of interest for 

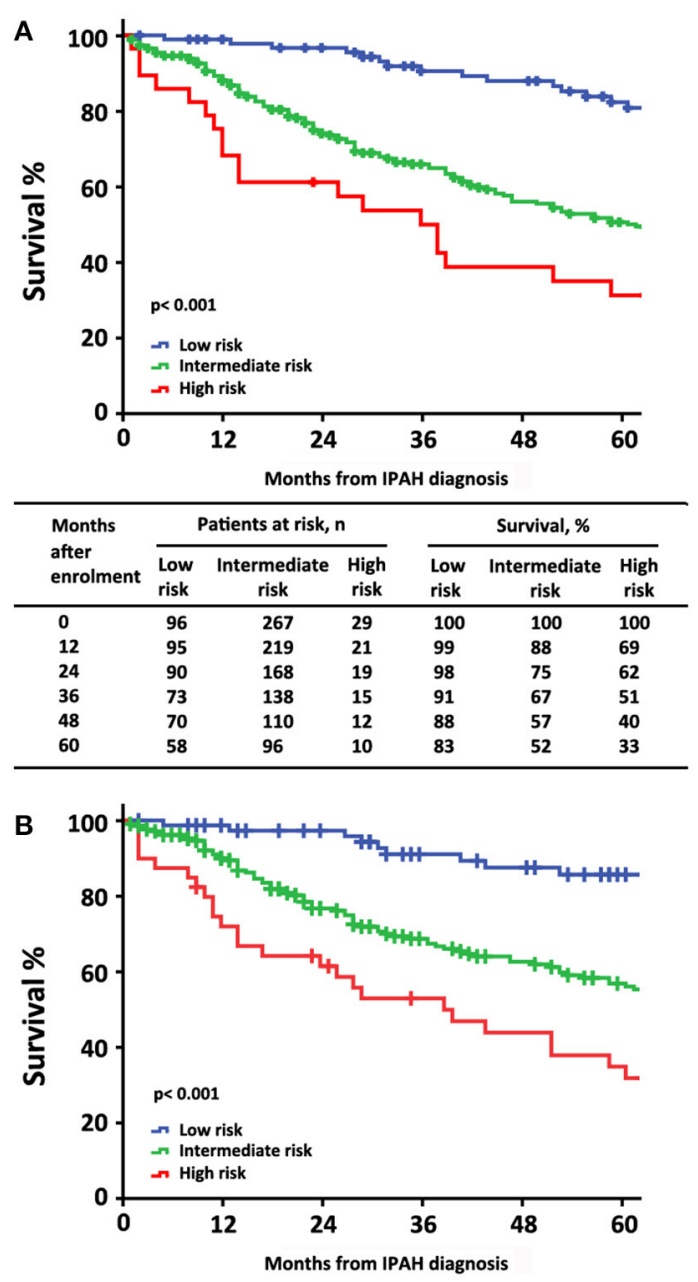

\begin{tabular}{lccccccc}
\hline \multirow{2}{*}{$\begin{array}{l}\text { Months } \\
\text { after } \\
\text { enrolment }\end{array}$} & \multicolumn{3}{c}{ Patients at risk, $\mathrm{n}$} & & \multicolumn{3}{c}{ Survival, \% } \\
\cline { 2 - 4 } \cline { 6 - 8 } & $\begin{array}{l}\text { Low } \\
\text { risk }\end{array}$ & $\begin{array}{c}\text { Intermediate } \\
\text { risk }\end{array}$ & $\begin{array}{l}\text { High } \\
\text { risk }\end{array}$ & & $\begin{array}{l}\text { Low } \\
\text { risk }\end{array}$ & $\begin{array}{c}\text { Intermediate } \\
\text { risk }\end{array}$ & $\begin{array}{l}\text { High } \\
\text { risk }\end{array}$ \\
\hline 0 & 76 & 207 & 39 & & 100 & 100 & 100 \\
12 & 75 & 170 & 28 & & 99 & 90 & 72 \\
24 & 70 & 130 & 23 & & 97 & 76 & 61 \\
36 & 56 & 104 & 19 & & 91 & 68 & 52 \\
48 & 49 & 88 & 15 & & 87 & 62 & 43 \\
60 & 46 & 74 & 12 & 85 & 56 & 34 \\
\hline
\end{tabular}

FIGURE 1 | The survival estimates in patients with idiopathic pulmonary arterial hypertension at baseline according to (A) the 2015 European Society of Cardiology/European Respiratory Society (ESC/ERS) risk stratification strategy; (B) a simplified version.

this study (Table 1). Out of the 10 variables at baseline, at least 4 variables were available in all the 392 patients, at least 10 in $59(15 \%)$ patients and at least 8 in $177(45 \%)$ patients. All the patients underwent the RHC examination. The characteristics of these patients in baseline were shown in Table 2. At the time of diagnosis, most patients $(67 \%)$ were women and mean age was 40 years old. A total of $260(67 \%)$ patients were in the WHO FC III or IV, whereas $34 \%$ patients were in the WHO FC I-II. All cause death survival for the overall study patients $(n=392)$ was shown in Supplementary Figure 1. For the initial treatment, 258 (66\%) patients received monotherapy, $101(26 \%)$ patients received combination therapy, and $33(8 \%)$ patients received no specific/calcium channel blocker (CCB) therapy. At baseline, 186 (48\%) patients used phospodiesterase 5 inhibitor (PDE5i) treatment in monotherapy group and 68 (17\%) patients used PDE5i plus endothelin receptor antagonist (ERA) (Supplementary Table 1).

\section{Risk Assessment at Baseline and Mortality}

At the time of diagnosis, 96 (25\%) of patients were in the low-risk group, 267 (68\%) of patients were in the intermediate-risk group, and $29(7 \%)$ of patients were in the high-risk group, respectively (Table 2). After the diagnosis of IPAH within 5 years, 141 (36\%) patients had died, 19 (20\%) patients were in the low-risk group, $104(39 \%)$ patients were in the intermediate-risk group, and 18 (62\%) patients were in the high-risk group. In the low-risk group, the survival rate at 1-, 2-, 3-, 4-, and 5-year was 99, 98, 91, 88, and $83 \%$, respectively. The corresponding survival was $88,75,67,57$, and $52 \%$ in the intermediate-risk group, respectively, and 69, 62, 51,40 , and $33 \%$ in the high-risk group, respectively $(p<0.001$ for all the group comparisons). The predictive values of each variable at baseline are shown in Figure 1A.

Similarly, by using simplified version, all the six variables were available in 322 patients, 76 (24\%) of patients were in the low-risk group, 207 (64\%) of patients were in the intermediate-risk group, and 39 (12\%) of patients were in the high-risk group, respectively (Supplementary Table 2). Accordingly, the survival differences in the three risk categories were still statistical significant $(p<$ 0.001 for all the group comparisons; Figure 1B). The predictive values of each variable in those patients at baseline are shown in Figure 2.

\section{Risk Assessment at Re-evaluation and Mortality}

At the end of follow-up, among the 106 patients with missing reevaluation information, 24 (6\%) patients died, 57 (15\%) patients were below two variables, and $25(6 \%)$ patients lost to followup for other specified reasons (Supplementary Figure 2). For re-evaluation assessment, out of the 10 variables, at least 2 variables were available in 286 patients, at least 8 variables were available in $11(4 \%)$ patients, and at least 4 variables were available in $210(73 \%)$ patients, respectively. Median interval between diagnosis and re-evaluation was $13[5,33]$ months. At the time of re-evaluation, 85 (30\%) patients were in the low-risk group, 159 (56\%) patients were in the intermediate-risk group, and $42(15 \%)$ patients were in the high-risk group, respectively. There were increased 5\% patients attaining high-risk group and decreased $12 \%$ patients with intermediate-risk group, although the percentage of low-risk group has an increased $8 \%(p<0.001$, Figure 3). Only $46(16 \%)$ of these re-evaluation patients were available for hemodynamic data; however, 186 (65\%) of these reevaluation patients were available for right area, $253(88 \%)$ of these re-evaluation patients were available for $\mathrm{PE}$, and 88 (31) of these re-evaluation patients were available for CPET.

The characteristics of these patients in re-evaluation were shown in Table 3. At re-evaluation, 147 (51\%) patients received monotherapy, 126 (44\%) patients received combination therapy, 


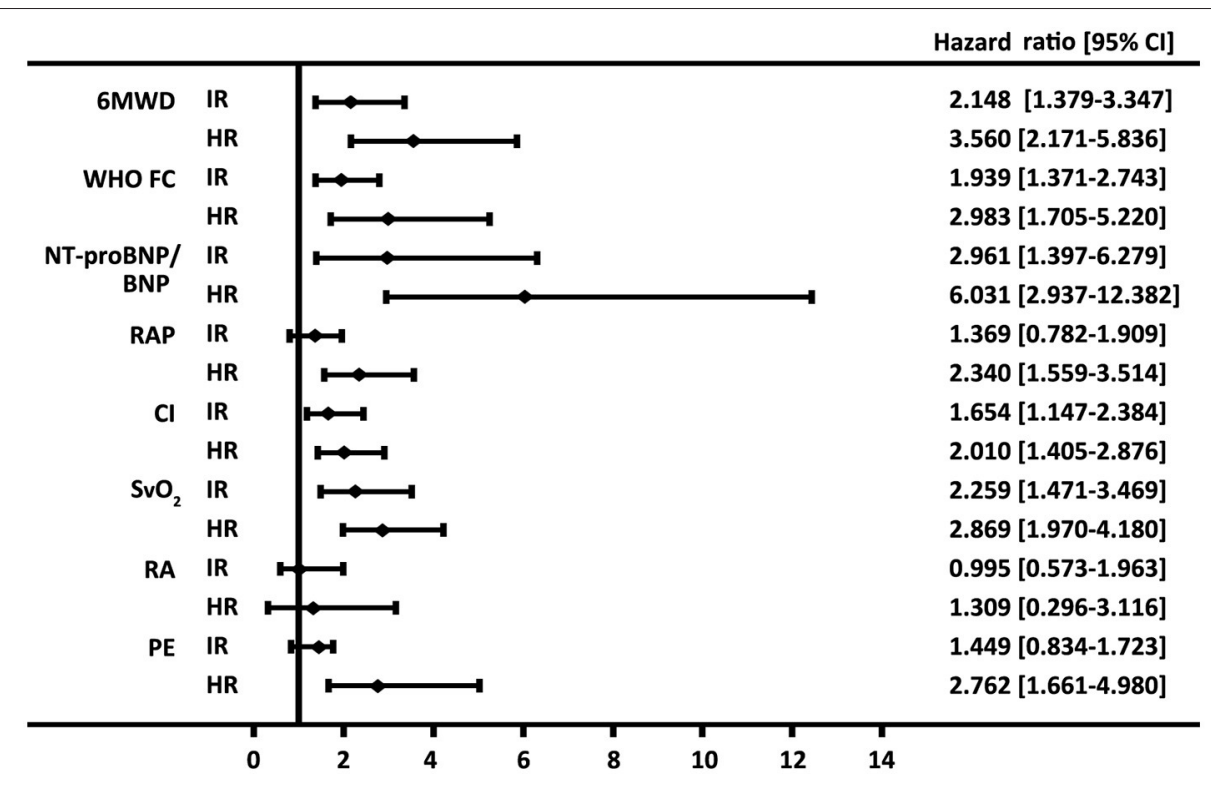

FIGURE 2 | Forest plot based on the prognostic values of 6-min walk distance (6MWD), the WHO function class (FC), brain natriuretic peptide (BNP) or N-terminal proBNP (NT-proBNP), right arterial pressure (RAP), cardiac index (Cl) and mixed venous oxygen saturation $\left(\mathrm{S}_{\mathrm{V}} \mathrm{O}_{2}\right)$, right atrium (RA) area, and pericardial effusion (PE) in the intermediate-risk (IR) and high-risk (HR) groups. Values for the variables were obtained from baseline. The reference value is from the respective low-risk group.

and $13(4 \%)$ patients received no specific/CCB therapy. Within combination therapy group, 102 (36\%) patients used PDE5i plus. Compared with those variables at baseline, there was significant improvement in 6MWD, CI, PVR, $\mathrm{S}_{\mathrm{V}} \mathrm{O}_{2}$, and proportion of combination therapy (Supplementary Table 3). After reevaluation of these patients within 5 years, 36 (13\%) patients had died, 4 (8\%) patients were in the low-risk group, $16(10 \%)$ patients were in the intermediate-risk group, 7 (17\%) patients were in the high-risk group, and $9(3 \%)$ patients in censor. In the low-risk group, the survival rate at 1-, 2-, 3-, 4-, and 5-year was $94,91,89,82$, and $76 \%$, respectively. The corresponding survival was $75,66,54,46$, and $38 \%$ in the intermediate-risk group, respectively, and $53,28,25,21$, and $18 \%$ in the high-risk group, respectively ( $p<0.001$ for all the group comparisons; Figure 4). The predictive values of each variable from the multivariate Cox proportional hazards regression analysis at re-evaluation are shown in Supplementary Figure 3. The WHO FC, 6MWD, $\mathrm{NT}$-proBNP/BNP, and $\mathrm{SVO}_{2}$ were independent predictors. From baseline to re-evaluation, the changes in the risk assessment were associated with a shift in the mortality risk $(p<0.001$ for all the group comparisons; Figure 5).

\section{DISCUSSION}

There was much evidence to support that the multiparametric approach stratified the patients with $\mathrm{PAH}$ in different risk groups for mortality. According to the risk status, different strategies can be utilized to guide therapeutic decisions (8). However, the validation of these comprehensive risk assessments for Chinese patients with IPAH is unclear. Among the above three registries, IPAH was a major etiology of PAH, such as

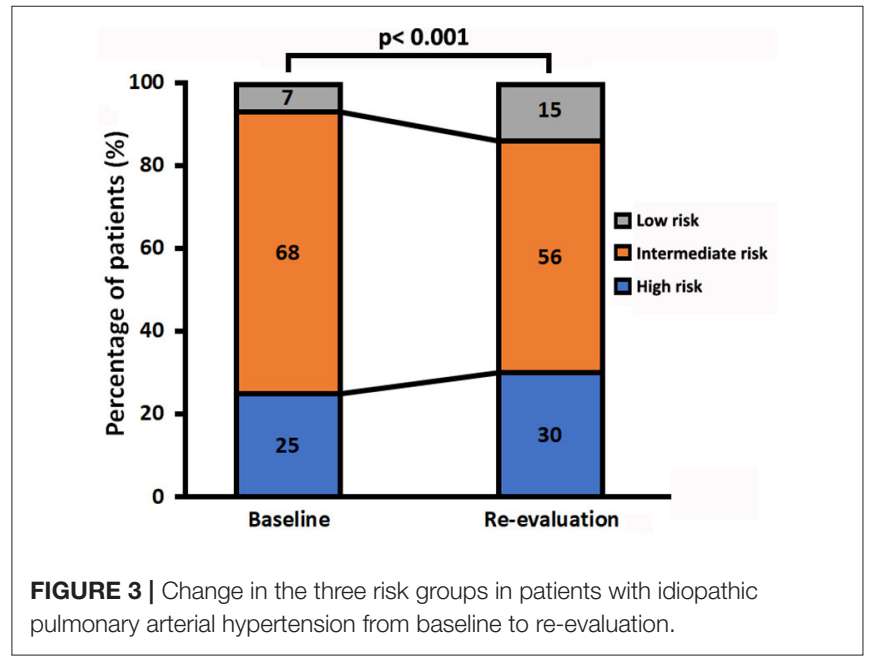

$77 \%$ in the FPHN, 67\% in the COMPERA Registry, and 51\% in the Swedish PAH Registry, which indicated that IPAH was a special type and provided available strategy (4-6). The main findings of this study can be demonstrated as follows: (1) the 2015 European PH guidelines risk stratification effectively discriminated a low, intermediate, and high risk at baseline and re-evaluation assessments; (2) accurately predicted the risk of death in patients with IPAH; (3) its simplified version risk strategy was valid for baseline; and (4) the percentage of the low-risk group has an increase at re-evaluation, but a greater proportion of patients achieved the high-risk group and a lesser proportion maintained in the intermediate-risk group. Despite of 
TABLE 3 | Characteristics of patients with IPAH in re-evaluation risk stratification.

\begin{tabular}{|c|c|c|c|c|c|}
\hline & $N$ & Low risk & Intermediate risk & High risk & All \\
\hline Subjects, $n$ (\%) & & $85(30)$ & $159(56)$ & $42(15)$ & 286 \\
\hline \multicolumn{6}{|l|}{ WHO FC, $n(\%)$} \\
\hline Class I-II & & $48(56)$ & $28(18)$ & $0(0)$ & $76(27)$ \\
\hline Class III & & $8(9)$ & $94(59)$ & $20(48)$ & $122(43)$ \\
\hline Class IV & & $0(0)$ & $6(4)$ & $19(45)$ & $25(9)$ \\
\hline 6MWD, meters & 135 & $472 \pm 69$ & $370 \pm 106$ & $204 \pm 154$ & $396 \pm 120$ \\
\hline BNP, ng/L & 43 & $25(13,42)$ & $297(150,453)$ & $726(385,874)$ & $184(64,453)$ \\
\hline NT-proBNP, ng/L & 224 & $74(40,142)$ & $1,160(541,2,403)$ & 1,691 (1,444, 2,844) & $806(146,2,326)$ \\
\hline \multicolumn{6}{|l|}{ Hemodynamics } \\
\hline RAP, $\mathrm{mmHg}$ & 46 & $5(3,7)$ & $10(6,12)$ & $12(5,14)$ & $6(4,11)$ \\
\hline mPAP, mmHg & 46 & $43(34,52)$ & $64(57,70)$ & $78(68,84)$ & $57(40,65)$ \\
\hline PAWP, mmHg & 46 & $9(7,11)$ & $10(6,11)$ & $10(8,14)$ & $10(7,11)$ \\
\hline $\mathrm{Cl}, \mathrm{L} / \mathrm{min} / \mathrm{m}^{2}$ & 46 & $3.5(3.2,4.6)$ & $2.3(1.9,2.6)$ & $1.9(1.6,2.0)$ & $2.6(2.2,3.4)$ \\
\hline PVR, Wood units & 46 & $5(4,8)$ & $15(12,20)$ & $21(17,22)$ & $10(5,15)$ \\
\hline $\mathrm{S}_{\mathrm{V}} \mathrm{O}_{2}, \%$ & 46 & $74(71,78)$ & $60(52,63)$ & $50(41,58)$ & $65(58,74)$ \\
\hline \multicolumn{6}{|c|}{ Echocardiographic variables } \\
\hline RA area, $\mathrm{cm}^{2}$ & 186 & $15(12,18)$ & $22(18,29)$ & $45(37,52)$ & $23(17,34)$ \\
\hline No PE, $n(\%)$ & & $74(87)$ & $91(57)$ & $19(45)$ & $170(67)$ \\
\hline Minimal PE, $n(\%)$ & & $2(2)$ & $45(28)$ & $12(29)$ & $73(29)$ \\
\hline $\mathrm{PE}, n(\%)$ & & $0(0)$ & $3(2)$ & $7(17)$ & $10(4)$ \\
\hline \multicolumn{6}{|c|}{ Cardiopulmonary exercise testing } \\
\hline Peak VO $2, \mathrm{~mL} / \mathrm{min} / \mathrm{kg}$ & 88 & $17 \pm 3$ & $12 \pm 3$ & $9 \pm 1$ & $13 \pm 4$ \\
\hline VENCOO 2 slope & 88 & $35 \pm 5$ & $56 \pm 25$ & $81 \pm 48$ & $52 \pm 28$ \\
\hline \multicolumn{6}{|c|}{ Therapies (within 3 months after re-evaluation), n (\%) } \\
\hline No specific/CCB therapy & & $5(6)$ & $7(4)$ & $1(2)$ & $13(4)$ \\
\hline Monotherapy & & $54(64)$ & $77(48)$ & $16(38)$ & $147(51)$ \\
\hline Combination therapy & & $26(31)$ & $75(47)$ & $25(60)$ & $126(44)$ \\
\hline
\end{tabular}

Values are expressed as mean $\pm S D$, medians (interquartile range), or $n(\%)$, unless otherwise stated.

BMI, body mass index; BNP, brain natriuretic peptide; CCB, calcium channel blocker; Cl, cardiac index; mPAP, mean pulmonary arterial pressure; 6MWD, 6-minute walk distance;

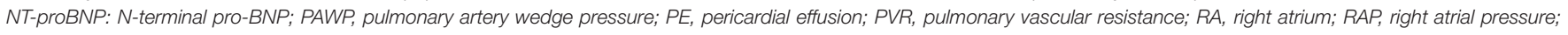
$\mathrm{SVO}_{2}$, mixed venous oxygen saturation; $\mathrm{VENCO} 2$, ventilatory equivalents for carbon dioxide; $\mathrm{VO}_{2}$, oxygen consumption; FC, function class.

the methodical risk assessments that are applicable for Chinese patients with IPAH, actual treatment seems not consistent with this goal-oriented treatment strategy.

A comprehensive assessment is used, since no single variable provides sufficient diagnostic and prognostic information. As we known, the 2015 ESC/ERS guidelines recommended 13 variables and the REVEAL risk score consisted of 19 variables $(1,2)$. The number of variables seems possible to discriminate risk groups accurately, but not all the variables may be done in $\mathrm{PH}$ centers. Except for the progression and syncope of the symptom, the variables selected in this study included all the RHC parameters, BNP or NT-proBNP, and 6WMD at baseline. Meanwhile, right atrium (RA) area was available in $235(60 \%)$ patients, PE was available in 357 (91\%) patients, and CPET was available in 100 (26\%) patients (Tables 2,3$)$. It was significantly discrimination of different risk groups, i.e., $25 \%$ patients were in the low-risk group, $68 \%$ patients were in the intermediate-risk group, and $7 \%$ patients were in the high-risk group, respectively. If we used the simplified version of risk criteria, the proportion of the highrisk group was increased to $12 \%$ (Supplementary Table 2). Our results were closed to previous findings by the Swedish $\mathrm{PH}$ Registry, which the proportion of low-, intermediate-, and highrisk patients, respectively, was 23,67 , and $10 \%$ (530 patients with $\mathrm{PAH}$ and $49 \%$ patients with IPAH) (4). However, in the COMPERA IPAH subgroup study, the proportion of the highrisk group increased to $19 \%$ (5). The reasons for differences are partly attributed to different variables used for risk assessment or severity of different parameters. For example, 6MWD was $299 \pm 123 \mathrm{~m}$ in the COMPERA IPAH subgroup, but $369 \pm$ $107 \mathrm{~m}$ in this study. Our previous study has been reported that 6-min walk test values in Chinese patients with IPAH were significantly higher than those recorded in foreign registries $(3,10-12)$. Hence, it is necessary to discuss the feasibility of statistical risk calculation method. Given that echocardiography and CPET were not available for all the studies, most reliable indicators needed to further determine.

Regardless of whether regular follow-up, the three risk groups had significantly different long-term survival at baseline and in re-evaluation. It suggested that 13 variables of the 2015 ESC/ERS guidelines were relatively stable to discriminate risk stratification. 
However, we still found that an increased proportion of the high-risk group and a lesser proportion of patients with the intermediate-risk group, although the percentage of the lowrisk group has an increase (Figure 3). The changes in risk category reflected that the patients in the low-risk group may be benefit from initial treatment, but those in the intermediateand high-risk groups seemed not be sufficient. In this study, primary combinations of PAH-targeted drugs were observed in $26 \%$ of all the patients and in $28 \%$ of the high-risk patients, which implicated that combination treatment goal was not achieved in majority of our patients. Ample evidence was proposed to use of initial monotherapy or combination therapies in patients with naïve $\mathrm{PAH}$ (13-19). Initial combination therapy could improve exercise capacity and prognosis compared with initial monotherapy $(14,17)$. It is intelligible that the treatment goals are not always realistic and physicians may modify the therapeutic strategies with advanced disease or severe comorbidities. Certainly, the improved survival rates may be attributable to success of specific treatment and the increasing economic burden for patients cannot be ignored (10, 19). Even at the time of re-evaluation, over $50 \%$ patients are still in monotherapy or no specific therapies condition after all.

Of note, the parameters of echocardiography and CPET were used for risk stratification in this study including RA area, $\mathrm{PE}$, peak $\mathrm{VO}_{2}$, and ventilatory equivalents for carbon dioxide $\left(\mathrm{VE} / \mathrm{VCO}_{2}\right.$ ) slope proposed by the $2015 \mathrm{PH}$ guidelines. Presence of $\mathrm{PE}$ is common and thought to be an important indicator for right heart failure in patients with PAH $(20,21)$. Fenstad et al. reported that even modest degrees of pericardial fluid were associated with a significant increase in mortality in patients with PAH (22). In this study, we also found the degree of severe $\mathrm{PE}$ in the high-risk group that may be overestimated (Table 3, Figure 3). A preserved RA function is crucial to maintain sufficient right heart function, partly since the change of RA size alters the motion of the tricuspid annulus (23). Accordingly, impaired right ventricle systolic function and RA dilation (RA area $>18 \mathrm{~cm}^{2}$ ) were associated with worse long-term survival in patients with IPAH $(24,25)$. Grapsa et al. have reported that clinical deterioration was better associated with RA rather than RV remodeling in patients with PAH (26). There was no difference of RA area between baseline and re-evaluation (median was $22 \mathrm{~cm}^{2}$ at baseline and $23 \mathrm{~cm}^{2}$ in re-evaluation). Our data suggested that the parameters of PE and RA area were useful information for the risk stratification strategy.

Cardiopulmonary exercise testing may provide suggestive information in patients with $\mathrm{PAH}$ both at the circulation impairment and ventilatory inefficiency (27). Lower peak $\mathrm{VO}_{2}$ and higher $\mathrm{VE} / \mathrm{VCO}_{2}$ slope were considered to establish the severity of exercise capacities or to assess outcomes (28-30). Wensel et al. have reported that average peak $\mathrm{VO}_{2}$ and $\mathrm{VE} / \mathrm{VCO}_{2}$ slope during exercise were $11.2 \pm 0.5 \mathrm{ml} / \mathrm{min} / \mathrm{kg}$ and $54 \pm 2$ (2002) (31) and $13 \pm 5 \mathrm{ml} / \mathrm{min} / \mathrm{kg}$ and $54 \pm 18$ (2013) (30), respectively; also, patients with peak $\mathrm{VO}_{2} \leq 10.4 \mathrm{ml} / \mathrm{min} / \mathrm{kg}$ had poor survival. Our data showed that peak $\mathrm{VO}_{2}$ was $14 \pm 4$ $\mathrm{ml} / \mathrm{min} / \mathrm{kg}$ and $\mathrm{VE} / \mathrm{VCO}_{2}$ slope was $54 \pm 2$ at baseline. Reference to the criteria of the 2015 ESC PH guidelines, the value of peak $\mathrm{VO}_{2}$ was arrived to the intermediate-risk group and $\mathrm{VE} / \mathrm{VCO}_{2}$

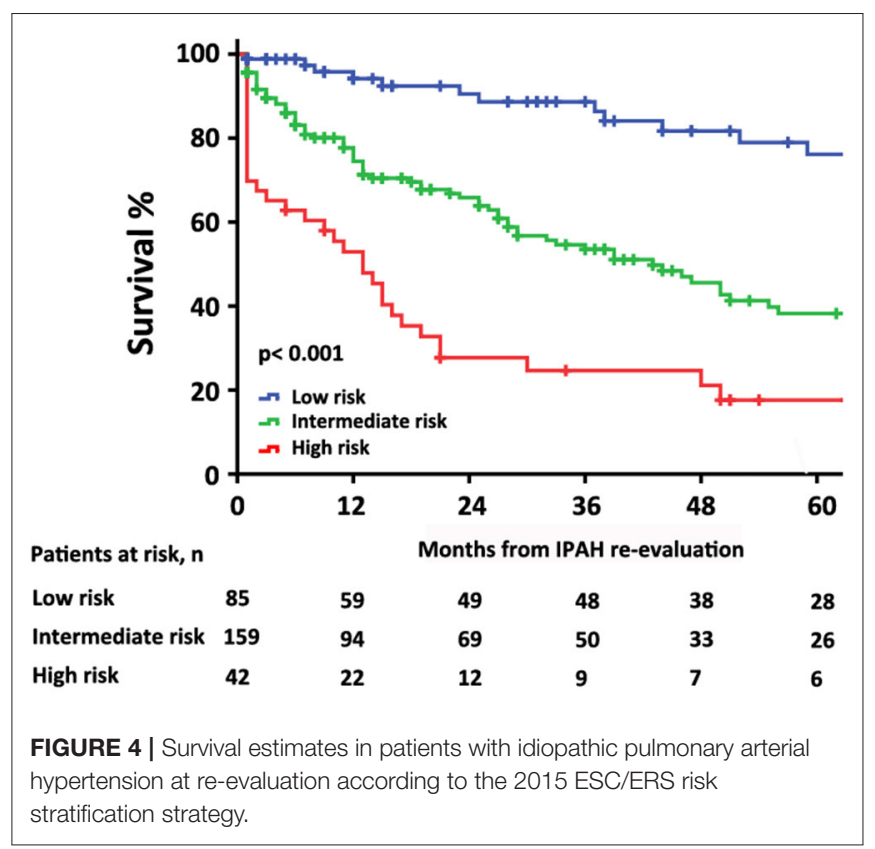

slope was arrived to the high-risk group in this study. However, the two variables of CPET were all removed from the Cox multivariate model equation (at last step). This does not mean that CPET per se is not relevant, but that exercise function might not be superior to resting hemodynamics or echocardiography in this study. Although CPET is not widely utilized in patients with $\mathrm{PAH}$, an increasing recognition of potential values should be emphasized (32). A total of 26\% (100/392) patients of this study have CPET values, but further studies need still more valuable information to evaluate comprehensive score system for risk.

\section{Study Limitations}

The major strengths of this study were the availability of complete data for invasive hemodynamics and non-invasive echocardiography and CPET variables at diagnosis in patients with IPAH. There are several limitations in this study. First, this is a retrospective study in a single center and the sample size was not large enough to provide sufficient numbers of the patients in three risk stratifications. Second, the followup assessments were not standardized and the proportion of RHC testing was lower at re-evaluation. However, we selected the follow-up visit that contained most of the data such as echocardiography or CPET. So, $88 \%$ patients at re-evaluation assessments had values of PE, 65\% patients at re-evaluation assessments had values of RA area, and $\sim 30 \%$ patients at reevaluation assessments had values of CPET. Additionally, despite of median interval between diagnosis and re-evaluation was 13 months, $\sim 15 \%$ of that was over 24 months, which may be biased toward the time-effect test. Finally, this study does not include prognostic variables, such as age, sex, comorbidities, disease progression, and syncope, and the individual risk is further modified by these factors. Further studies should 


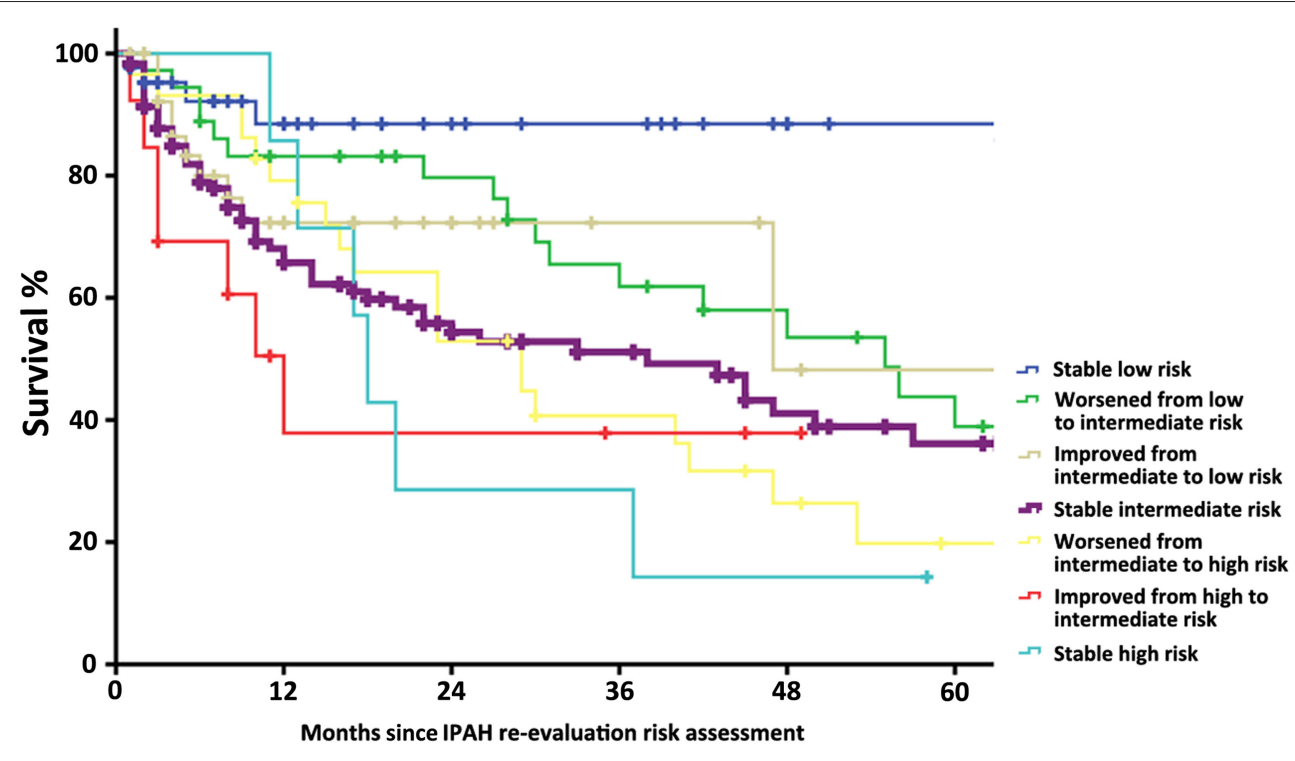

\begin{tabular}{|c|c|c|c|c|c|c|c|}
\hline \multirow[b]{2}{*}{$\begin{array}{l}\text { Months } \\
\text { after } \\
\text { enrolment }\end{array}$} & \multicolumn{7}{|c|}{ Patients at risk, $n$} \\
\hline & $\begin{array}{l}\text { Stable } \\
\text { low risk }\end{array}$ & $\begin{array}{l}\text { Worsened from } \\
\text { low to } \\
\text { intermediate risk }\end{array}$ & $\begin{array}{l}\text { Improved from } \\
\text { intermediate to } \\
\text { low risk }\end{array}$ & $\begin{array}{c}\text { Stable } \\
\text { intermediate risk }\end{array}$ & $\begin{array}{l}\text { Worsened from } \\
\text { intermediate } \\
\text { to high risk }\end{array}$ & $\begin{array}{l}\text { Improved from } \\
\text { high to } \\
\text { intermediate risk }\end{array}$ & $\begin{array}{l}\text { Stable } \\
\text { high risk }\end{array}$ \\
\hline 0 & 43 & 36 & 41 & 117 & 29 & 13 & 7 \\
\hline 12 & 30 & 30 & 19 & 58 & 23 & 6 & 6 \\
\hline 24 & 25 & 24 & 11 & 39 & 15 & 4 & 2 \\
\hline 36 & 25 & 18 & 7 & 31 & 11 & 4 & 2 \\
\hline 48 & 25 & 13 & 4 & 20 & 6 & 4 & 1 \\
\hline \multirow[t]{2}{*}{60} & 23 & 9 & 3 & 14 & 4 & 4 & 1 \\
\hline & \multicolumn{7}{|c|}{ Survival, \% } \\
\hline $\begin{array}{l}\text { Months } \\
\text { after } \\
\text { enrolment }\end{array}$ & $\begin{array}{l}\text { Stable } \\
\text { low risk }\end{array}$ & $\begin{array}{l}\text { Worsened from } \\
\text { low to } \\
\text { intermediate risk }\end{array}$ & $\begin{array}{l}\text { Improved from } \\
\text { intermediate to } \\
\text { low risk }\end{array}$ & $\begin{array}{c}\text { Stable } \\
\text { intermediate risk }\end{array}$ & $\begin{array}{l}\text { Worsened from } \\
\text { intermediate } \\
\text { to high risk }\end{array}$ & $\begin{array}{l}\text { Improved from } \\
\text { high to } \\
\text { intermediate risk }\end{array}$ & $\begin{array}{l}\text { Stable } \\
\text { high risk }\end{array}$ \\
\hline 0 & 100 & 100 & 100 & 100 & 100 & 100 & 100 \\
\hline 12 & 97 & 83 & 80 & 66 & 79 & 84 & 71 \\
\hline 24 & 95 & 80 & 76 & 54 & 53 & 69 & 57 \\
\hline 36 & 92 & 62 & 72 & 51 & 45 & 61 & 29 \\
\hline 48 & 92 & 58 & 48 & 43 & 40 & 51 & 29 \\
\hline 60 & 89 & 44 & 48 & 36 & 26 & 40 & 14 \\
\hline
\end{tabular}

FIGURE 5 | The survival estimates in patients with idiopathic pulmonary arterial hypertension according to the 2015 ESC/ERS risk category from baseline to re-evaluation. This figure was based on $n=286$ patients.

organize more prospective studies or explore exiting registries in China.

\section{CONCLUSION}

In conclusion, the present data show that the 2015 ESC/ERS $\mathrm{PH}$ guidelines and its simplified version risk stratification strategy may effectively discriminate different risk groups at baseline and re-evaluation. Meanwhile, this study validated an accurate prediction of mortality. Non-invasive echocardiography assessment might help to identify predictive usefulness of risk categorization strategies. The parameters of CPET seems to be less sensitive to the risk level designation, but need to be clarified in future and prospective studies. Changes of risk proportion at re-evaluation implicated that natural treatment decisions may not behave consistently with goal-oriented treatment strategy, but patients with IPAH may benefit from initial therapy.

\section{DATA AVAILABILITY STATEMENT}

The raw data supporting the conclusions of this article will be made available by the authors, without undue reservation.

\section{ETHICS STATEMENT}

The studies involving human participants were reviewed and approved by K19-054. The patients/participants provided their written informed consent to participate in this study. 


\section{AUTHOR CONTRIBUTIONS}

RZ and LW contributed to the study design, study conduct, supervision, scientific overview, data analysis, editing of the manuscript, and also directly involved in the recruitment and care of the patients. S-GG and W-HW contributed to enrolment of the patient, data analysis, scientific interpretation, drafting, and editing the original manuscript. CL, Q-HZ, RJ, C-JL, H-LQ, and J-ML contributed to recruitment of participants, data collection, curation, and formal analysis. All authors have reviewed the manuscript, approved the final version for submission, participated in the design of this study, patient enrolment, and meet criteria for authorship.

\section{FUNDING}

This study was supported in part by the National Natural Science Foundation of China (82000059) (LW), the

\section{REFERENCES}

1. Galie N, Humbert M, Vachiery JL, Gibbs S, Lang I, Torbicki A, et al. 2015 ESC/ERS Guidelines for the diagnosis and treatment of pulmonary hypertension: The Joint Task Force for the Diagnosis and Treatment of Pulmonary Hypertension of the European Society of Cardiology (ESC) and the European Respiratory Society (ERS): Endorsed by: Association for European Paediatric and Congenital Cardiology (AEPC), International Society for Heart and Lung Transplantation (ISHLT). Eur Heart J. (2016) 37:67-119. doi: 10.1093/eurheartj/ehv317

2. Benza RL, Gomberg-Maitland M, Miller DP, Frost A, Frantz RP, Foreman AJ, et al. The REVEAL Registry risk score calculator in patients newly diagnosed with pulmonary arterial hypertension. Chest. (2012) 141:35462. doi: 10.1378/chest.11-0676

3. Benza RL, Miller DP, Foreman AJ, Frost AE, Badesch DB, Benton WW, et al. Prognostic implications of serial risk score assessments in patients with pulmonary arterial hypertension: a Registry to Evaluate Early and Long-Term Pulmonary Arterial Hypertension Disease Management (REVEAL) analysis. J Heart Lung Transplant. (2015) 34:356-61. doi: 10.1016/j.healun.2014. 09.016

4. Kylhammar D, Kjellstrom B, Hjalmarsson C, Jansson KJ, Nisell M, Soderberg $\mathrm{S}$, et al. A comprehensive risk stratification at early follow-up determines prognosis in pulmonary arterial hypertension. Eur Heart J. (2018) 3947:417581. doi: 10.1093/eurheartj/ehx257

5. Hoeper MM, Kramer T, Pan Z, Eichstaedt CA, Spiesshoefer J, Benjamin N, et al. Mortality in pulmonary arterial hypertension: prediction by the 2015 European pulmonary hypertension guidelines risk stratification model. Eur Respir J. (2017) 50:1700740. doi: 10.1183/13993003.00740-2017

6. Boucly A, Weatherald J, Savale L, Jais X, Cottin V, Prevot G, et al. Risk assessment, prognosis and guideline implementation in pulmonary arterial hypertension. Eur Respir J. (2017) 502:1700889. doi: 10.1183/13993003.00889-2017

7. Galie N, Channick RN, Frantz RP, Gruing E, Jing ZC, Olga M, et al. Risk stratification and medical therapy of pulmonary arterial hypertension. Eur Respir J. (2019) 53:1801889. doi: 10.1183/13993003.01889-2018

8. Diller GP, Dimopoulos K, Okonko D, Li W, Babu-Narayan SV, Broberg CS, et al. Exercise intolerance in adult congenital heart disease: comparative severity, correlates, and prognostic implication. Circulation. (2005) 112:82835. doi: 10.1161/CIRCULATIONAHA.104.529800

9. Badagliacca R, Poscia R, Pezzuto B, Papa S, Reali M, Pesce F, et al. Prognostic relevance of right heart reverse remodeling in idiopathic pulmonary arterial hypertension. J Heart Lung Transplant. (2017) S1053-2498:320417. doi: 10.1016/j.healun.2017.09.026
Project of International Cooperation (19410741000) (RZ) and (201409004100) (S-GG) in Science and Technology Commission Shanghai Municipality, and the Youth Scholar Program of Shanghai Pulmonary Hospital (fkgg1804) (RZ).

\section{ACKNOWLEDGMENTS}

The authors acknowledge the contribution of all the investigators who participated in this study. We also thank the patients who participated in this study.

\section{SUPPLEMENTARY MATERIAL}

The Supplementary Material for this article can be found online at: https://www.frontiersin.org/articles/10.3389/fcvm. 2021.745578/full\#supplementary-material

10. Zhang R, Dai LZ, Xie WP, Yu ZX, Wu BX, Pan L, et al. Survival of Chinese patients with pulmonary arterial hypertension in the modern treatment era. Chest. (2011) 140:301-9. doi: 10.1378/chest.10-2327

11. Benza RL, Miller DP, Gomberg-Maitland M, Frantz RP, Foreman AJ, Coffey CS, et al. Predicting survival in pulmonary arterial hypertension: insights from the Registry to Evaluate Early and Long-Term Pulmonary Arterial Hypertension Disease Management (REVEAL). Circulation. (2010) 122:16472. doi: 10.1161/CIRCULATIONAHA.109.898122

12. Humbert $M$, Sitbon O, Chaouat A, Bertocchi M, Habib G, Gressin V, et al. Pulmonary arterial hypertension in France: results from a national registry. Am J Respir Crit Care Med. (2006) 173:1023-30. doi: 10.1164/rccm.200510-1668OC

13. Lajoie AC, Lauziere G, Lega JC, Lacasse Y, Martin S, Simard S, et al. Combination therapy versus monotherapy for pulmonary arterial hypertension: a meta-analysis. Lancet Respir Med. (2016) 4:291-305. doi: 10.1016/S2213-2600(16)00027-8

14. GalieN, Barbera JA, Frost AE, Ghofrani HA, Hoeper MM, McLaughlin $\mathrm{VV}$, et al. Initial use of Ambrisentan plus Tadalafil in pulmonary arterial hypertension. N Engl J Med. (2015) 373:834-44. doi: 10.1056/NEJMoa1413687

15. PulidoT, Adzerikho I, Channick RN, Delcroix M, Galie N, Ghofrani HA, et al. Macitentan and morbidity and mortality in pulmonary arterial hypertension. N Engl J Med. (2013) 369:809-18. doi: 10.1056/NEJMoa1213917

16. Hassoun PM, Zamanian RT, Damico R, Lechtzin N, Khair R, Kolb TM, et al. Ambrisentan and Tadalafil up-front combination therapy in sclerodermaassociated pulmonary arterial hypertension. Am J Respir Crit Care Med. (2015) 192:1102-10. doi: 10.1164/rccm.201507-1398OC

17. Sitbon O, Channick R, Chin KM, Frey A, Gaine S, Galie N, et al. Selexipag for the treatment of pulmonary arterial hypertension. N Engl J Med. (2015) 373:2522-33. doi: 10.1056/NEJMoa1503184

18. GalieN, Palazzini M, Manes A. Pulmonary arterial hypertension: from the kingdom of the near-dead to multiple clinical trial meta-analyses. Eur Heart J. (2010)31:2080-6. doi: 10.1093/eurheartj/ehq152

19. Wu WH, Yang L, Peng FH, Yao J, Zou LL, Liu D, et al. Lower socioeconomic status is associated with worse outcomes in pulmonary arterial hypertension. Am J Respir Crit Care Med. (2013) 187:30310. doi: 10.1164/rccm.201207-1290OC

20. Batal O, Dardari Z, Costabile C, Gorcsan J, Arena VC, Mathier MA. Prognostic value of pericardial effusion on serial echocardiograms in pulmonary arterial hypertension. Echocardiography. (2015) 32:1471-6. doi: 10.1111/echo.12909

21. Austin C, Burger C, Kane G, Safford R, Blackshear J, UngR, et al. Highrisk echocardiographic features predict mortality in pulmonary arterial hypertension. Am Heart J. (2017) 189:167-76. doi: 10.1016/j.ahj.2017.04.013 
22. Fenstad ER, Le RJ, Sinak LJ, Maradit-Kremers H, Ammash NM, Ayalew $\mathrm{AM}$, et al. Pericardial effusions in pulmonary arterial hypertension: characteristics, prognosis, and role of drainage. Chest. (2013) 144:15308. doi: 10.1378/chest.12-3033

23. Hernandez-Suarez DF, Lopez Menendez FL, Lopez-Candales A. Maximal systolic excursion of the tricuspid annulus is independent of right atrial size and function in chronic pulmonary hypertension. Echocardiography. (2017) 34:810-6. doi: 10.1111/echo.13531

24. D'Alto M, D’Andrea A, DiSalvo G, Scognamiglio G, Argiento $\mathrm{P}$, Romeo E, et al. Right atrial function and prognosis in idiopathic pulmonary arterial hypertension. Int J Cardiol. (2017) 248:320-5. doi: 10.1016/j.ijcard.2017.08.047

25. Roca GQ, Campbell P, Claggett B, Solomon SD, Shah AM. Right atrial function in pulmonary arterial hypertension. Circ Cardiovasc Imaging. (2015) 8:e003521. doi: 10.1161/CIRCIMAGING.115. 003521

26. Grapsa J, Gibbs JS, Cabrita IZ, WatsonGF, PavlopoulosH, DawsonD, et al. The association of clinical outcome with right atrial and ventricular remodelling in patients with pulmonary arterial hypertension: study with real-time threedimensional echocardiography. Eur Heart J Cardiovasc Imaging. (2012) 13:666-72. doi: 10.1093/ehjci/jes003

27. Weatherald J, Farina S, Bruno N, Laveneziana P. Cardiopulmonary exercise testing in pulmonary hypertension. Ann Am Thorac Soc. (2017) 14:S8492. doi: 10.1513/AnnalsATS.201610-788FR

28. Sun XG, Hansen JE, Oudiz RJ, Wasserman K. Exercise pathophysiology in patients with primary pulmonary hypertension. Circulation. (2001) 104:42935. doi: 10.1161/hc2901.093198

29. Wensel R, Opitz CF, Anker SD, Winkler J, Hoffken G, Kleber FX, et al. Assessment of survival in patients with primary pulmonary hypertension: importance of cardiopulmonary exercise testing. Circulation. (2002) 106:31924. doi: 10.1161/01.CIR.0000022687.18568.2A
30. Wensel R, Francis DP, Meyer FJ, Opitz CF, Bruch L, Halank M, et al. Incremental prognostic value of cardiopulmonary exercise testing and resting haemodynamics in pulmonary arterial hypertension. Int J Cardiol. (2013)167:1193-8. doi: 10.1016/j.ijcard.2012.03.135

31. Blumberg FC, Arzt M, Lange T, Schroll S, Pfeifer M, Wensel R. Impact of right ventricular reserve on exercise capacity and survival in patients with pulmonary hypertension. Eur J Heart Fail. (2013)15:7715. doi: 10.1093/eurjhf/hft044

32. Arena R, Lavie CJ, Milani RV, Myers J, Guazzi M. Cardiopulmonary exercise testing in patients with pulmonary arterial hypertension: an evidence-based review. J Heart Lung Transplant. (2010) 9:159-73. doi: 10.1016/j.healun.2009.09.003

Conflict of Interest: The authors declare that the research was conducted in the absence of any commercial or financial relationships that could be construed as a potential conflict of interest.

Publisher's Note: All claims expressed in this article are solely those of the authors and do not necessarily represent those of their affiliated organizations, or those of the publisher, the editors and the reviewers. Any product that may be evaluated in this article, or claim that may be made by its manufacturer, is not guaranteed or endorsed by the publisher.

Copyright (c) 2021 Gong, Wu, Li, Zhao, Jiang, Luo, Qiu, Liu, Wang and Zhang. This is an open-access article distributed under the terms of the Creative Commons Attribution License (CC BY). The use, distribution or reproduction in other forums is permitted, provided the original author(s) and the copyright owner(s) are credited and that the original publication in this journal is cited, in accordance with accepted academic practice. No use, distribution or reproduction is permitted which does not comply with these terms. 